
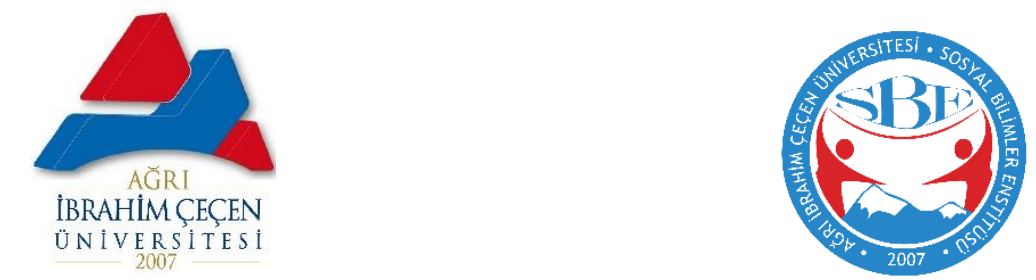

TÜRK KÜLTÜRÜNDE TOPA DARA (SOPA TOPU)

"Topa Dara" in Turkish Culture

\title{
Metin BAYRAM
}

Doç. Dr. Ağrı Ibrahim Çeçen Üniversitesi, Beden Eğitimi ve Spor Yüksekokulu metinbayram04@hotmail.com

iD https://orcid.org/0000-0002-7328-2526

\section{Serkan Tevabil AKA}

Dr. Öğr. Üyesi, Ağrı ibrahim Çeçen Üniversitesi, Beden Eğitimi ve Spor Yüksekokulu aka_serkan@hotmail.com

iD https://orcid.org/0000-0003-3048-3261

\section{Gökhan BAYRAKTAR}

Prof. Dr. Ağrı ibrahim Çeçen Üniversitesi, Beden Eğitimi ve Spor Yüksekokulu gokbayraktar@gmail.com https://orcid.org/0000-0002-8408-3143

\section{Kenan ŞEBIN}

Doç. Dr. Atatürk Üniversitesi, Kazım Karabekir Eğitim Fakültesi Beden Eğitimi ve Spor Öğretmenliği kenansebin@hotmail.com https://orcid.org/0000-0003-3078-6887

Ağrı ibrahim Çeçen Üniversitesi Sosyal Bilimler Enstitüsü Dergisi-Journal of Ağrı ibrahim Çeçen University Social Sciences Institute AiCUSBED 5/1 Nisan/April 2019 / Ağrı

\section{ISSN: 2149-3006} e-ISSN: $2149-4053$

\begin{tabular}{|l|l|}
\hline Makale Türü-Article Types : & Araştırma Makalesi \\
\hline Geliş Tarihi-Received Date $:$ & 03.01 .2019 \\
\hline Kabul Tarihi-Accepted Date : & 07.02 .2019 \\
\hline Sayfa-Pages $: 15-21$ & \\
\hline
\end{tabular}

http://dergipark.gov.tr/aicusbed

This article was checked by

$\checkmark$ iThenticate 



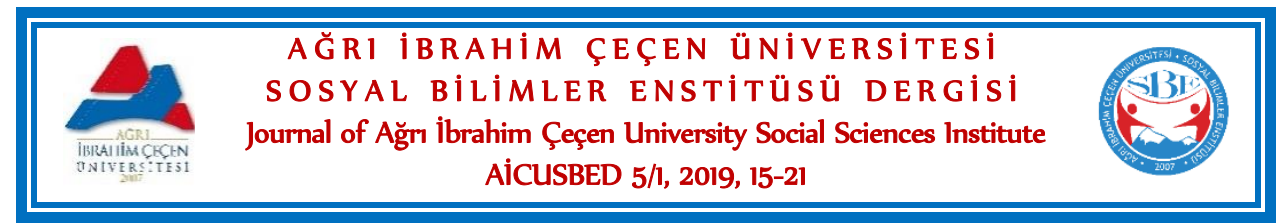

\section{TÜRK KÜLTÜRÜNDE TOPA DARA (SOPA TOPU)* \\ "Topa Dara" in Turkish Culture}

Doç. Dr. Metin BAYRAM, Dr. Öğr. Üyesi Serkan Tevabil AKA, Prof. Dr. Gökhan BAYRAKTAR, Doç. Dr. Kenan ŞEBiN

Özet

İnsan topluluklarını millet yapan en önemli unsur, kültürdür. Kültür; insanın, kendisine ve dünyaya, yaradılışııın dışında armağan ettiği maddi ve manevi değerlerin bir bütünü ve bu bütünlüğün bir kuşaktan diğerine aktarılmasıdır. Bu önemli değerlerden birisi de spordur. Spor, hareket etme, eylemde bulunma gibi anlamları ifade etmektedir. Ayrıca spor, belirli bir sistem çerçevesinde, belirli prensipler ve otoriteye dayalı yapılan eylemlerin rekorla sonuçlandırılmasını amaçlayan etkinlikler olarak da tanımlanmaktadır. Geniș bir coğrafyaya egemen olan Türkler birçok spor faaliyetinin öncülüğünü yapmıştır. Göç ettikleri her coğrafyada Türk kültüründen kaynaklanan sporları yaşatmış, geleneksel hale getirmiş ve kuşaklara aktarmak için çaba harcamışlardır. Bu sporlardan birisi de Türkiye'nin belirli bölgelerinde top ve sopa ile oynanmış olan “Topa Dara (Topa Garane)" oyunudur.

Bu çalışmanın amacı Türk kültür ve spor tarihinde önemli yeri olan bu oyunun geniş bir perspektif ile araştırılması, ulusal ve uluslararası düzeyde tanitılmasıdır.

Çalışmada geçmişin ışı̆ı̀nda, günümüzdeki durumu belirlemek için kullanılan gözden geçirme, derleme yöntemi kullanılmıştır. Veri toplama aracı olarak ise mülakat ve doküman analizi yöntemleri kullanılmıştır.

Elde edilen veriler ışığında oyunun tarihçesi, yapısı, kuralları, saha ve malzeme bilgisi hakkında birçok bulgular elde edilmiştir.

Sonuç olarak oyunun 1800 'lü yıllardan daha öncesine dayandı̆̆ı, özellikle Doğu Anadolu Bölgesi'nde oynandığı anlaşımaktadır. Yapısı itibariyle Amerika'da oynanan beysbol oyunu ile benzeştiği ancak birebir etkileşimin olamayacağı anlaşılmaktadır. Oyunda kullanılan sopa ve topun halen oyuncular tarafından doğal ürünler kullanılarak yapıldığı görülmüştür. Son yıllarda oyunun unutulmaya yüz tuttuğu, belirli köyler dışında genel olarak yeni kuşaklar tarafindan oynanmadığı tespit edilmiştir.

$\mathrm{Bu}$ ve benzeri geleneksel oyunların yaşatılması ve daha kurumsal hale getirilerek sürdürülebilmesi kültür açısından önem arz etmektedir.

Anahtar Kelimeler: Türk Spor Kültürü, Geleneksel Sporlar, Topa Dara. 
Doç. Dr. Metin BAYRAM, Dr. Öğr. Üyesi Serkan Tevabil AKA,

Prof. Dr. Gökhan BAYRAKTAR, Doç. Dr. Kenan ŞEBIN

\section{Abstract}

The most important element that makes human societies a nation is culture. Culture is the whole of the material and spiritual values that man gives to humanity and to the world without god's gift, and it is also the transfer of this integrity from one generation to the next. One of these important values is sport. Sport expresses meaning such as moving and acting. In addition, sports are defined as activities aimed at achieving success with certain principles and authority-based actions within a specific system. Turks dominating a wide geography have pioneered many sports activities. In every geography they migrated, they made the sports originating from the Turkish culture alive and made efforts to transfer them to the generations. One of these sports is Topa Dara (Topa Garane) which is played with ball and stick in certain regions.

The aim of this study is to investigate this game which has an important place in Turkish culture and sports history with a wide perspective, and to introduce it at national and international level.

In the light of the past, review method was used among the research methods used to indicate the current situation. Interview method and document analysis methods were used as data collection tool.

In the light of the gathered data many findings such as history, structure, rules, field and material knowledge of the game were obtained.

As a result, it is understood that the game dating back to 1800 s was played in the Eastern and South-eastern Anatolia Region. It's like a baseball game in the United States, but it's not the same. It is seen that the stick and ball used in the game are still made up of natural products created by the players themselves. In recent years, it has been determined that the game has not been played by new generations except for certain villages where the game is about to be forgotten.

Keeping these and similar traditional games alive and sustaining them with more institutionalization is important for the culture.

Key Words: Turkish Sport Culture, Traditional Sports, Topa Dara.

\section{Giriş}

Kültür; insanın, kendisine ve dünyaya, yaradılışının dışında armağan ettiği maddi ve manevi değerlerin bir bütünü ve bu bütünlüğün bir kuşaktan diğerine aktarılmasıdır (Erkal, Güven \& Ayan, 1998). İnsanların yaşam kültürü ve alışkanlıkları yaşadıkları topluma göre farklılıklar arz eder (Atabeyoğlu, Cem 2000).

Insan topluluklarını millet yapan önemli kültür unsurlarından birisi de spordur. Spor; Orta Çă̆ Latincesinde, disportare ve deportare kelimelerinden türemiştir. Bu kavramlar, hareket etme, eylemde bulunma gibi anlamları ifade etmektedir (Kale, 2007; Güngör, 1986). Ayrıca spor, belirli bir sistem çerçevesinde, belirli prensipler ve otoriteye dayalı yenme ve muktedir olma gibi insanın şuuraltı arzularının tatminini amaç edinen, rekabete dayalı, sosyalleştirici ve bütünleştirici etkinlikler olarak da tanımlanmaktadır (Türkiye'de Spor Eğitimi ve Politikası, 2009).

http://dergipark.gov.tr/aicusbed 5/1 Nisan / April 2019 
Her toplumun kendine özgü olan gelenekleri, tutkuları ve alışkanlıkları, toplumun genel yapısını belirleyebilmektedir. Toplumlar coğrafi konumlarına, geleneklerine, kültür birikimlerine ve kültür özelliklerine göre farklı spor dallarına ağırlık vermektedirler (Johnson, 1990). Spor, kültürün bir parçası olarak hem ondan etkilenmekte hem de popülerliği ve sosyalliği nedeniyle onu etkileyebilmektedir (Adamkiewicz, 1998).

Türk kültüründe de sportif etkinlikler hemen her alana sirayet etmiş ve Türk toplumunun en önemli unsurlarından birisi haline gelmiştir. Kişisel olduğu kadar sosyal ve toplumsal yönü de olan sporun toplumsal hayat içerisindeki varlığı ile gerek daha sağlıklı bireyler yetiştirilmiş, gerekse de askeri anlamda önemli başarılar elde edilmiştir (Gumilev, 1999; Güven, 1992). Türk toplumunun sosyal tarih akışındaki dönemler, olaylar ve yaşantılar Türk spor kültürünü de şekillendirmiştir. Dinamik bir toplum olan Türklerde spor, sosyal yaşamın da bir parçası olmuştur (URL2). Türkler göç ettikleri her coğrafyada Türk kültüründen kaynaklanan sporları yaşatmış, geleneksel hale getirmiş ve kuşaklara aktarmak için çaba harcamışlardır. Çağlar boyunca Türklerin yapmış oldukları sporların bir kısmı şekil değiştirerek popüler spor dalı olarak yapılmakta, bir kısmı yapısı değiştirilmeden geleneksel olarak devam ettirilmektedir. Bir kısmı ise devam ettirilemeyerek unutulmaya yüz tutmuştur (Yetim, 2000; Erkal, 1986).

Türk spor kültürün unutulmaya yüz tutmuş sportif etkinliklerinin yaşatılamaması ve gelecek kuşaklara aktarılamaması problem teşkil etmektedir. Bunlardan birisi de belirli bölgelerde top ve sopa ile oynanmış olan “Topa Dara (Topa Garane)" oyunudur. Türk kültür ve spor tarihinde önemli yeri olan bu ve benzeri sporların, ulusal ve uluslararası düzeyde tanıtılması ve yeni kuşaklara aktarılması bu çalışmanın genel amacını, Doğu Anadolu ve Güneydoğu Anadolu Bölgeleri'nde oynandığı bilinen yöresel ismiyle “Topa dara” oyunun geniş bir perspektif ile araştırılması ise çalışmanın temel amacını ortaya koymaktadır.

\section{Yöntem}

Çalışmada geçmişin ışı̆̆ında, günümüzdeki durumu belirtmek için kullanılan araştırma yöntemlerinden gözden geçirme derleme yöntemi kullanılmıştır. Veri toplama aracı olarak; sosyal bilimlerde kullanılan, bilgi alınacak kişilerle karşılıklı konuşma yoluyla bilgilerin birinci kaynaktan elde edilmesi ve araştırmacıya daha geniş bilgi edinme imkânı sunması bakımından fayda sağlayan görüşme (mülakat) yöntemi ve yanı sıra doküman analizi yöntemi kullanılmıştır.

Topa Dara oyununu oynamış veya izlemiş oldukları bilinen, yaşları 70 ve 95 arasında Doğu Anadolu Bölgesi'nden ve Güneydoğu Anadolu Bölgesi'nden kişilerle mülakat yapılmıştır. Ayrıca bu bölgelere sınırı olan İran, Suriye ve lrak gibi ülkelerin sınıra yakın Ürümiye, Hoy, Mako, Süleymaniye ve Dohok şehirlerinden konu ile ilgisi olabilecek akademisyenler ve yerel halktan kişilerle de temas kurularak veri toplanmaya çalışılmıştır.

\section{Bulgular}

http://dergipark.gov.tr/aicusbed 5/1 Nisan / April 2019 
Doç. Dr. Metin BAYRAM, Dr. Öğr. Üyesi Serkan Tevabil AKA,

Prof. Dr. Gökhan BAYRAKTAR, Doç. Dr. Kenan ŞEBIN

Topa Dara; diğer bir ifadeyle "topa garane" en az 6 en fazla 12 kişi ile iki takım halinde her hangi bir süre olmaksızın sayı ve oyun sistemine göre belirlenmiş bir açık alan üzerinde top ve sopa ile oynanan yöresel bir oyundur. Genellikle Doğu ve Güneydoğu Anadolu Bölgelerinde oynandığı bilinmektedir.

“Topa dara” yöresel dilde top ve ağaç veya sopa, farklı bir ifade ediliş şekli olan "topa garani” ise kalabalıkla top oynamak anlamları taşımaktadır (Halis Bayram, kişisel görüşme, Haziran 2018).

Oyunun tarihini belirlemek oldukça zordur. Ancak mülakatlardan elde edilen bulgulara göre oyunun 1800'lü yıllara dayandığı hatta daha önceki tarihlerde de bölge insanları tarafindan oynanmış olabileceği görülmektedir. Geçmişi oldukça eski yıllara dayanan topa dara oyunun bölgede yaşayan insanların kültürlerinin bir parçası olduğu görülmektedir (Celal Afşsin, kişisel görüşme, Haziran 2018). Oyunun yapısı itibariyle Amerika'da popüler olan beyzbol ile ileri derecede benzerlikler gösterdiği görülmektedir (Mohamad Heydarzadeh, kişisel görüşme, Mayıs 2018). Bu iki oyunun birbirlerinden coğrafi ve kültürel olarak etkilenmiş olabilme olasılığı çok düşüktür.

Beyzbol tarihi incelendiğinde kökenlerinin Eski Mısır'da top ve sopa ile oynanan bir oyuna dayandırıldığı görülmektedir. Ayrıca 2000 yıl öncesinden kaldığı bilinen buna benzer bir topun Londra'daki British Museum'da sergilendiği bilinmektedir (WBSC, 2018).

Genel olarak top ve sopayla oynanan oyunların geçmişine bakıldığında bugünlerde Romanya'nın bir parçası olan Walacchia'da oynanmış bir oyunun var olduğu, 14. Asırda Rusya'da benzer bir oyunun oynandığı, 1330'lu yıllarda Fransız rahipler arasından top ve sopayla oynanan popüler benzer bir oyunun olduğu, William Pagula isimli bir şairin Stoolball isminde bir oyundan bahsettiği; bahiste süt sağan bir genç kızın yeni budanmış bir sopa ile kriket benzeri bir oyun oynadığı görülmektedir. Ayrıca Almanların Schlagball isimli 12 kişilik takımlarla oynanan bir oyunu oynadıkları halen de Kiel bölgesinde geleneksel olarak oynamaya devam ettikleri bilinmektedir. 19. Asırda Amerika'da "townball” ismiyle oynanmaya başlanan beyzbol oyunun da köken olarak İngiliz adasında 1600'lü yıllarda oynanan "rounders" olarak ifade edilen bir oyuna dayandı̆̆ı görülmektedir. Öte yandan rounders ve beyzbol oyunlarının da 14. Asırda Flaman çobanlarının oynadığı kriket oyununa dayandırıldı̆̆ı görülmektedir (WBSC,2018).

Türk kültüründe yer alan ve çok geniş coğrafyalarda oynanan özellikle top ve sopa ile oynanan çoğu oyunların Asya kökenli olduğu bilinmektedir. Bunların başında “çevgen" gelmektedir. Elde edilen bu bulgulara baktığımızda Avrupa'da özellikle İngiltere adasında görülen oyunların kökenin aslında Asya kökenli olduğu söylenebilir. Bu durumu İngilizlerin izledikleri sömürü politikalarına dayandırmak mümkündür.

Oyunda kullanılan malzemelerle ilgili elde edilen bilgilere göre; Topun, büyükbaş hayvanların tüyleri ile koyunyünü karıştırılıp keçe haline gelinceye dek yoğrularak elde edildiği anlaşılmaktadır (Abdullah Sarı, kişisel görüşme, Mayıs 2018).

http://dergipark.gov.tr/aicusbed 5/1 Nisan / April 2019 
Topun vuruş esnasında hızlı yol almaya başlaması ancak yünden yapılmış olduğu için hava teması ile kısa sürede hızının kesilerek yavaşlaması oyuna ayrı bir özellik katmaktadır. Bu özelliği sayesinde oyunu oynamış olan kişilerin daha fazla zevk aldıkları ve daha az çaba sarf ettikleri kendi beyanlarından ortaya çıkmaktadır (Esmaeil jabbarza, kişisel görüşme, Mayıs 2018). Oyunda kullanılan sopanın ise 50 $\mathrm{cm}$ veya $60 \mathrm{~cm}$ uzunluğunda bir ağacın düz, pürüzsüz ve hafif yatsı bir şekle getirilmesiyle oluşturulduğu görülmektedir. Kıyafet olarak oyunun günlük kıyafetlerle oynandığı görülmekte, herhangi bir özel kıyafetin kullanılmadığı anlaşılmaktadır. Elde edilen bulgulara göre oyun alanı ölçülerinin kesin ve net olmadığı ancak 40 veya 50 metre uzunluğunda yine aynı genişlikte düz, geniş, yumuşak zeminli ve açık alanlarda oynandığı anlaşılmaktadır. Biçilmiş çayırlar veya kar üzerinde oynandığı da görülmektedir (Khaled ibrahim, kişisel görüşme, Mayıs 2018).

Oyunun yapısı ve kurallarına bakıldığında genel olarak topa dara oyunu 6 savunma 6 hücum oyuncusu olmak üzere 2 takımdan oluşmaktadır. Oyuna kimin başlayacağına kura ile karar verilir. Bir savunma bir de hücum oyuncusu tespit edilir, diğer oyuncular alanda belirlenen yerlere dağılır. Savunma yapan takımın oyuncuları alanda rahatça hareket edebilirler. Hücum oyuncuları ise alanlarını terk etmezler. Beyzbol oyununa benzer bir şekilde savunma oyuncusu topu havaya kaldırır hücum oyuncusu topa vurur, top havalanır havalanmaz takım arkadaşlarından birinin ismini söyleyerek yer değiştirmeye çalışır. Bu esnada savunma oyuncuları ismi okunan kişiye topu vurmaya çalışırlar. Topun ismi söylenen kişiye teması halinde yer değiştirilir. Oyuncular bulundukları yerde uzun süreli bekleyemezler mutlaka bir isim okunup baştaki hedefe bir oyuncunun geçmesi gerekir. Bu esnada sporcu kendisine topun değmemesi için bireysel yeteneklerini ortaya koymalıdır. Örneğin yere yatabilir, zıplayabilir vs. ancak topa vuruş esnasında savunma oyuncuları topu havada yakalamışlarsa; takımlar hücum ve savunma olarak yer değiştirirler. Oyundan çıkan kişi kenarda bekler, son oyuncu oyundan çıkana kadar devam eder (Celal Afşin ve Abdullah Sarı, kişisel görüşme, Haziran 2018).

Yapılan görüşmelerde bölgede oynanan bu oyunun diğer sporlar kadar zevkli olduğu, uzun yıllar geleneksel olarak oynandığı, bölge yaşayan pek çok kişinin beğenisini kazanmış olduğu ve belli dönemlerde özellikle köylerde en çok tercih edilen oyunlardan biri olduğu görülmektedir.

Oyunun gençler tarafından son zamanlara kadar Ağrı, Van, Bitlis, Muş, Hakkâri illerinin merkez, ilçe ve köylerinde oynandığı bilinmekte, bazen bu kültürün yaşatılması için bazı çalışma ve projelerin yapıldığı da görülmektedir. Hakkâri Üniversitesi Projeler Birimi tarafından hazırlanıp Gençlik ve Spor Bakanlığı tarafından desteklenen Yeşeren Ümitler Projesi kapsamında uzun yıllardan sonra bu oyunun tekrar oynatılması, Van, Erciş ilçesi, İşbaşı köyü muhtarı ve köylülerinin de asırlardır yaşatmaya çalıştıkları oyun ile ilgili ulusal basında yer almaları bu gelişmelerden bazılarıdır.

Sonuç ve Öneriler

http://dergipark.gov.tr/aicusbed 5/1 Nisan / April 2019 
Doç. Dr. Metin BAYRAM, Dr. Öğr. Üyesi Serkan Tevabil AKA,

Prof. Dr. Gökhan BAYRAKTAR, Doç. Dr. Kenan ŞEBIN

Elde edilen bulgular ışığında “Topa Dara” oyununun Doğu ve Güneydoğu Anadolu Bölgesinde çok uzun zaman öncesinden oynanmaya başladığı ve son dönemlere kadar oynadığı sonucuna varılmaktadır. Top ve sopa ile oynan oyunun yapısı itibariyle günümüz beyzbol sporuna benzediği ancak benzeşmenin ve etkileşimin nereden kaynaklandığı bilinmemektedir. Oyunun Orta Asya kökenli olma olasılığı daha yüksek bir ihtimaldir. Sonuç olarak son yıllarda Topa dara oyununun unutulmaya yüz tuttuğu belirli köyler dışında genel olarak yeni kuşaklar tarafindan oynanmadığı görülmüştür. Türk spor kültürünün bir parçası olma özelliği taşıyan ve günümüz koşullarında unutulmaya yüz tutmuş bu ve benzeri oyunların ulusal ve uluslararası ortamlarda tanıtılması, çeşitli etkinlikler aracılığıyla yaygınlaştırılması ve yaşatılması gerekmektedir.

Anayasanın 59. maddesinde yer alan "sporun gelişmesine ve yaygınlaştırılmasına yönelik politikalara öncelik verilmelidir" ibaresine istinaden bu ve buna benzer Türk kültürüne ait geleneksel sporların üzerinde daha fazla durulmalıdır. Ülke sporunun kalkınması geleneksel sporların yaşatılması açısından başta Gençlik ve Spor Bakanlı̆̆ı ve Millî Eğitim Bakanlı̆̆ı olmak üzere federasyonlar, üniversiteler ve kulüplerin önemli görev ve sorumluluk almaları gerekmektedir. Geleneksel Spor Dalları federasyonun da bu ve buna benzer spor dalları ile ilgili akademisyen ve araştırmacılarla işbirliği içerisinde kalarak önemli kurumsal sorumluluk üstlenmesi gerekmektedir.

Her çocuğun Türk spor kültürü içerisinde önemli yeri olan geleneksel spor dallarına yönelik ilgileri ebeveynler tarafından artırılmalıdır.

Genel çerçeveden bakıldığında Türk sporuna ayrılan bütçe arttırılmalı, kamu kurum ve kuruluşları ile belediyelerin aktif katılımları sağlanmalı, basın yayın organlarının bu konuda daha geniş bir yelpazede yayın yapmaları gerekliliği ortaya konmalıdır.

$\mathrm{Bu}$ ve benzeri geleneksel oyunların yaşatılması ve daha kurumsal hale getirilerek sürdürülebilmesi kültür açısından önem arz etmektedir.

\section{Kaynakça}

Adamkiewicz, E. (1998), Spor sokak gösterileri. Lyon'da muhteşem özerk spor aktiviteleri. Gelen Kentsel Research Annals (Cilt. 79, No. 1, sf. 50-57). Kentsel Araştırma Merkezi.

Atabeyoğlu, Cem (2000), Geleneksel Türk Güreşi ve Kırkpınar, 5, istanbul: Türkiye Milli Olimpiyat Komitesi Yayınları.

Erkal, M., Özbay G. \& Ayan, D. (1998), Sosyolojik Açıdan Spor, Genişletilmiş 3.Baskı, Topkapi/istanbul: Eren Ofset.

Erkal, M. (1986), Sosyolojik Açıdan Spor, ı.Baskı, 10000 Adet, Ankara: Milli Eğitim Basımevi.

Gumilev, L, N. (1999), Eski Türkler, Çev: D. A. Batur, Birleşik Yayıncılı: İstanbul.

Güngör, E. (1986), Kültür Değişmesi ve Milliyetçilik, Ötüken NeşriyatA.Ş., Ankara, s.66-67.

http://dergipark.gov.tr/aicusbed 5/1 Nisan / April 2019 
Güven, Ö. (1992), Türkler'de Spor Kültürü, Atatürk Kültür Merkezi Yayınları: Ankara. Johnson, M.O., (1990), Children, adolescent and television,(American Academy of Pediatric), Pediatrics, Volume:6, p.:1119-1120.

Kale, R. (2007), ilköğretimde Beden Eğitimi ve Oyun Öğretimi. Ankara: Pegem A Yayıncilı.

Şahin, M. H. (2006), Beden Eğitimi ve Spor Sözlüğü. İstanbul: Morpa Kültür Yayınları.

URLı, (2009) Spor ve Spor Kültürüne Genel Bakış, http://www.sporbilim.com/spor.html. Erişim Tarihi: 20.04.2018.

WBSC, (2018). http://www.wbsc.org/baseball/history-of-baseball/ Erişim Tarihi: 17.05.2018.

Yetim, A. A. (2005), Sosyoloji ve Spor. İstanbul: Morpa Kültür Yayınları. 